\title{
REVIEW \\ Epidemiology of traumatic spinal cord injury: trends and future implications
}

\section{MJ DeVivo}

Study design: Review supplemented by inception cohort.

Objectives: To review trends in the incidence, prevalence, demographic characteristics, etiology, injury severity and selected treatment outcomes of traumatic spinal cord injury (SCI).

Setting: International review and US model systems cohort.

Methods: An extensive literature review was conducted to identify all relevant studies of descriptive epidemiology of traumatic SCI. This review was supplemented by analyses of trends in US SCl epidemiology that are reflected in the National Spinal Cord Injury Statistical Center and Shriners Hospital Spinal Cord Injury databases.

Results: Incidence and prevalence of traumatic SCI in the United States are higher than in the rest of the world. Average age at injury is increasing in accordance with an aging general population at risk. The proportion of cervical injuries is increasing, whereas the proportion of neurologically complete injuries is decreasing. Injuries due to falls are increasing. Recent gains in general population life expectancy are not reflected in the SCI population. Treatment outcomes are changing as a result of increasing age and changes in US health care delivery.

Conclusion: Within the prevalent population, the percentage of elderly persons will not increase meaningfully until the high mortality rates observed among older persons significantly improve. Those who reach older ages will typically have incomplete and/or lower level injuries, and will have relatively high degrees of independence and overall good health.

Spinal Cord (2012) 50, 365-372; doi:10.1038/sc.2011.178; published online 24 January 2012

Keywords: spinal cord injury; epidemiology; mortality

\section{INTRODUCTION}

Spinal cord injury (SCI) epidemiology has been studied extensively over the past 40 years. Initial studies focused on descriptive epidemiology, including overall incidence rates, age, gender, race, cause of injury, level and completeness of injury. ${ }^{1-3}$

In the early 1970's, the model SCI care system program was initiated in the United States with a requirement that all model systems submit data on patients they treated to what is now known as the National Spinal Cord Injury Statistical Center (NSCISC) database. ${ }^{4}$ In 1987, three Shriners Hospital SCI units started the Shriners Hospital Spinal Cord Injury (SHSCI) database in parallel with the NSCISC database. These two databases have been combined and used extensively to develop a descriptive profile of SCI in the United States and to evaluate trends in that profile over time. ${ }^{5-9}$ Unfortunately, these databases are not population-based. As a result, they cannot be used to evaluate trends in underlying incidence rates. However, these databases have large sample sizes, geographic diversity, a wide range of longitudinal information and an excellent data quality. ${ }^{10,11}$

Beginning in the 1980s, several statewide population-based SCI surveillance systems (registries) were established. ${ }^{12-16}$ These were used to evaluate potential biases in the NSCISC database, and taken together, helped to produce a relatively complete picture of SCI epidemiology in the United States during the 1980s and 1990s. ${ }^{17}$ Unfortunately, most of these state registries no longer exist, and therefore it is not possible to evaluate actual SCI incidence rate trends in the United States. Moreover, although many studies have been conducted in other countries, many of these have been limited in duration and not repeated, thereby making assessment of international trends in SCI incidence and prevalence extremely difficult. ${ }^{18}$

\section{METHODS}

\section{Literature search}

An extensive literature review was conducted to identify all relevant studies of the descriptive epidemiology of SCI. The original search was made using Google Scholar with the words spinal cord injury and either incidence, prevalence, epidemiology or etiology included in the title. This resulted in 303 total citations, some of which, such as articles on the incidence or prevalence of specific complications after SCI, were not relevant to the current review. The reference lists of each of these publications were also checked for additional citations not already identified. Internet sites of prominent SCI organizations and governmental agencies such as the Christopher and Dana Reeve Foundation, National Spinal Cord Injury Association, Paralyzed Veterans of America, Miami Project to Cure Paralysis, Rick Hansen Institute, Australian Institute of Health and Welfare, European Spinal Cord Injury Federation, National Institute on Disability and Rehabilitation Research, and National Institute on Neurological Disorders and Stroke, that provide descriptive information to professionals and consumers were also checked for results of any unpublished studies. 


\section{NSCISC and SHSCI databases}

The NSCISC and SHSCI databases have been described in detail elsewhere. ${ }^{7,10,11}$ Eligibility criteria for the NSCISC database include having a traumatic SCI, being admitted to the SCI Model System within 1 year of injury, residing within the geographical catchment area of the SCI Model System (to facilitate follow-up), either completing rehabilitation within the SCI Model System, recovering within 7 days without rehabilitation, or dying during the SCI Model System hospitalization and informed consent. Enrollment in the SHSCI database requires a traumatic SCI and admission to a Shriners Hospital SCI unit, but there are no length of time to admission and geographical restrictions. In each case, the treating physician confirms eligibility for enrollment in the database.

For purposes of this review, the NSCISC and SHSCI databases were combined into a single data set (subsequently referred to as the combined US data set), and the usual eligibility criteria for inclusion in the NSCISC and SHSCI databases were relaxed to include a broader range of persons with SCI that would be more suitable for an epidemiological study. For example, the usual requirements that persons be admitted within 1 year of injury and reside in the geographical catchment of the SCI model system were waived. Therefore, although the first SCI model systems were funded in 1973, some persons included in the combined US data set used for this review were injured long ago as in 1935. Nonetheless, $99 \%$ of persons in this combined US data set were injured since 1970. Collectively, model SCI care systems and Shriners Hospital SCI units treat approximately $13 \%$ of all new SCIs that occur in the United States each year. ${ }^{10}$

\section{Statistical analysis}

Estimates of the characteristics of the incident and prevalent population of SCI in the United States were derived from the combined US data set and are expressed as means for continuous items and percentages for categorical items. The incident population included 45442 new injuries that occurred between 1935 and 2008. The prevalent population included a subset of 24631 persons from the combined US data set who were still alive in December 2008. The physical and psychological outcomes of those prevalent cases were also compared across years post-injury and age using data obtained in 20062008. Tests of statistical significance of trends over time were based on the Pearson's $\chi^{2}$-test for categorical data and one-way analysis of variance for continuous items.

Annual mortality rates for persons enrolled in the combined US data set were determined by creating a person-year data set in which each year of follow-up for each person was treated as a separate observation. ${ }^{19}$ Thus, a person who was followed for 5 years and died during the fifth year would contribute five observations to the data set. The person in this example would be considered alive at the end of each of the first four observations and dead for the fifth observation. Using this approach resulted in a person-year data set of 541181 observations from which annual mortality rates was calculated.

\section{RESULTS AND DISCUSSION}

\section{Overall incidence}

Published reports of SCI incidence in the United States vary from 25 to 59 new cases per million population per year with an average of 40 per million. ${ }^{12-16}$ This would translate to approximately 12400 new SCIs in 2010 (http://www.census.gov/compendia/statab/cats/ population/estimates_and_projections_by_age_sex_raceethnicity.html. Accessed 1/2/2011). One study published in 2000 failed to find any significant trend in SCI incidence rates over time, but this study is now $>10$-year-old. ${ }^{20}$ There have not been any new studies of SCI incidence in the United States in more than a decade. Moreover, because of changes in participating model systems every 5 years, as well as the combined US data set's lack of a population basis, the combined US data set is not suitable to evaluate incidence rates. It can only be used to evaluate trends in characteristics of persons with SCI and only if one assumes that there are no trends in any underlying biases that the data set may have. Nonetheless, if one assumes a constant overall incidence rate, then based on US population projections, the incidence of new SCIs would increase to 13600 in 2020, 14960 in 2030, 16240 in 2040 and 17560 in 2050 (http://www.census.gov/compendia/statab/ cats/population/estimates_and_projections_by_age_sex_raceethnicity. html. Accessed 1/2/2011).

The incidence of SCI in the rest of the world is much lower than in the United States. ${ }^{18}$ There are several possible explanations for this. One is the relative absence in most countries of SCI because of acts of violence. However, there also appear to be fewer SCIs related to motor vehicle crashes in other countries. Possible explanations for this would be a lower average passenger miles of exposure, greater use of seat belts, or safer driving habits and road conditions. Conversely, lower incidence could also result from greater mortality at the site of the accident. Finally, incomplete case ascertainment may have occurred in many of these studies as they are not typically population-based but rather rely on referrals to specialized centers. No studies have addressed the reasons for international variation in SCI incidence.

Two recent Scandinavian studies have evaluated trends in incidence rates over the past few decades. In Norway, the SCI incidence rate was 6.2 per million population from 1952 to 1956 , but had increased to 26.3 per million population from 1997 to $2001 .^{21}$ Part of this trend could be the result of increasing survival rates at the scene of the accident. Nonetheless, there was an increased incidence of motor vehicle-related injuries during the observation period, especially among men $<30$ years of age, as well as an increased incidence of injuries due to falls. ${ }^{21}$ Incomplete cervical injuries also increased, especially among men $>60$ years of age. ${ }^{21}$ Conversely, in Finland, no trend in age-adjusted SCI incidence rates was observed from 1976 to 2005; however, there was an increase in the SCI incidence rate among persons aged $>55 .{ }^{22}$ Recent Australian studies have evaluated trends in SCI incidence between 1986 and 1997 and projected future incidence rates through 2021 under a variety of assumptions. ${ }^{23,24}$ No change in the overall age-standardized incidence rate was observed, but incidence rates decreased over time for young males and motor vehicle crashes whereas increasing for elderly males and falls. ${ }^{23}$ Additional studies are needed before any meaningful conclusions can be drawn about trends in worldwide SCI incidence rates.

\section{Demographic characteristics of incident cases}

Age at injury. SCI incidence rates are lowest for the pediatric age group, highest for persons in their late teens and early twenties, and generally decline consistently thereafter, although some studies suggest a secondary increase in incidence rates among the elderly. ${ }^{12,15,21}$ Among persons enrolled in the combined US data set, the mean age at injury has increased from 28.3 years during the 1970 s to 37.1 years between 2005 and 2008. ${ }^{9}$ These figures mirror the increasing median age of the general US population, which was 30 years in 1980 and 36.9 years in 2010 (http://www.census.gov/compendia/statab/cats/ population/estimates_and_projections_by_age_sex_raceethnicity.html. Accessed 1/2/2011). More specifically, the proportion of new injuries that were at least 60 years of age at injury increased from $4.6 \%$ in the 1970 s to $13.2 \%$ between 2005 and $2008 .^{9}$ This is slightly greater than the change in the US population, where the proportion of the people aged $\geqslant 65$ increased from $11.3 \%$ in 1980 to $13.0 \%$ in 2010 (http:// www.census.gov/compendia/statab/cats/population/estimates_and_ projections_by_age_sex_raceethnicity.html. Accessed 1/2/2011).

The median age of the US population is projected to continue to increase, but at a reduced pace, from 36.9 years in 2010 to 38.7 years in 2030, and 39.0 years in 2050 (http://www.census.gov/compendia/ statab/cats/population/estimates_and_projections_by_age_sex_raceeth nicity.html. Accessed 1/2/2011). Moreover, the proportion of people in the United States who are $\geqslant 65$ of age is also projected to increase from $13.0 \%$ in 2010 to $16.1 \%$ in 2020 , and $20.2 \%$ by 2050 
(http://www.census.gov/compendia/statab/cats/population/estimates_ and_projections_by_age_sex_raceethnicity.html. Accessed 1/2/2011). Therefore, assuming underlying age-specific incidence rates do not change, the average age when new SCIs occur in the United States will likely continue to increase, perhaps by 2 years in the next decade and lesser amounts each decade through at least 2050. The percentage of new injuries that are at least 60 years of age will continue to increase as well, perhaps by $2 \%$ over the next decade and lesser amounts thereafter.

The average age at injury is a few years higher in most other countries than in the United States. ${ }^{18}$ This is likely because of the lower rate of injuries due to violence that typically occur among younger persons, although other factors such as the average age of the general population and differences in other cause-specific incidence rates also likely have a role in raising the average age at injury in other countries. In $2001,13 \%$ of the US population was $>65$ years, compared with $18 \%$ in Japan and $15 \%$ in Europe (http://www. theusaonline.com/people/age.htm. Accessed 1/2/2011).

Gender. SCI occurs predominantly among men and will continue to do so in the future. SCI annual incidence rates are typically 3 to 4 times higher for men than women. ${ }^{18}$ However, the percentage of new injuries occurring among men in the combined US data set has declined slightly over time from $80.9 \%$ during the 1970 s to $77.1 \%$ since $2000 .{ }^{18}$ A similar trend has occurred in Norway where the incidence rate was 5.3 times higher among males than females between 1952 and 1956, but only 4.2 times higher between 1992 and $2001 .^{21}$ This trend toward a slightly increasing percentage of women among new SCIs should continue because injuries among older persons are increasing, and SCIs among the elderly are more evenly split between men and women than SCIs that occur among teenagers and young adults.

Etiology of injury. In the United States, motor vehicle crashes are the leading cause of SCI. ${ }^{9,12,15,18}$ Although the percentage of SCIs owing to motor vehicle crashes in the combined US data set has fluctuated over time, it is approximately the same today (48.3\% since 2000$)$ as it was during the 1970 s $(47.6 \%) .{ }^{18}$ Injuries due to acts of violence peaked in the 1990 s $(21 \%)$ but have since declined dramatically (12\% since 2000). ${ }^{18}$ Overall, sports-related SCIs have declined slightly from $14.2 \%$ during the 1970 s to $10.0 \%$ since $2000 .{ }^{18}$ Injury prevention initiatives have reduced the occurrence of SCIs in many sports, most notable diving, American football and trampolines. However, SCIs from winter sports such as snow skiing have increased.

Falls are the leading cause of SCI among persons aged $>60{ }^{15}$ Therefore, it is not surprising that the proportion of new SCIs owing to falls has been increasing steadily as injuries among older persons have become more frequent. During the 1970s, falls accounted for $16.2 \%$ of new SCIs in the combined US data set compared with $21.8 \%$ since $2000 .^{18}$ This trend is likely to continue, with a corresponding decline in sports and violence-related SCIs that do not typically occur among older persons.

Severity of injury. There is substantial international variability in the proportion of new SCIs resulting in tetraplegia and the proportion of neurologically complete injuries. ${ }^{18}$ In Europe, the proportion of cervical injuries ranges from approximately 40 to $60 \%{ }^{18}$ In the Middle East where more injuries are due to acts of violence, the proportion of cervical injuries is at the lower end of the European range. ${ }^{18}$ In the United States, $55.7 \%$ of new injuries enrolled in the combined US data set since 2000 were cervical injuries. ${ }^{18}$

Several long-term studies have recently reported on possible trends in injury levels over time. In Germany, there was no significant trend in the proportion of cervical injuries between 1976 and $1996{ }^{25}$ However, other studies suggest an increase in cervical injuries. In Finland, the proportion of cervical injuries increased from 48 to $57 \%$ over a 30-year period between 1976 and $2005 .^{22}$ In Australia, the percentage of incomplete tetraplegia is forecast to increase in the coming years. ${ }^{24}$ In the combined US data set, the percentage of cervical injuries increased from $50.7 \%$ during the 1970 s to $55.7 \%$ since $2000 .^{18}$

Interestingly, in the United States, this increase in cervical injuries is due entirely to an increase in C1-C4 lesions from 12.3 to $27.2 \%$ whereas C5-C8 injuries actually decreased from 35.9 to $29.0 \%{ }^{9}$ Moreover, this increase in high level cervical injuries has also resulted in a doubling of the percentage of persons being discharged ventilatordependent, from $1.5 \%$ in the 1970 's to $5.4 \%$ between 2000 and 2004 before declining slightly to $4.6 \%$ after $2004 .^{9}$

Assessing trends in neurological completeness of injury are complicated by changing definitions over time. Nonetheless, it appears that there are more incomplete injuries today than in the past. In the combined US data set, the proportion of complete injuries decreased from $53.6 \%$ during the 1970 s to $48.7 \%$ since $2000 .{ }^{18}$ As indicated previously, Australian projections call for an increase in incomplete tetraplegia. ${ }^{24}$ The percentage of complete injuries is also on the decline in Finland. ${ }^{22}$

There are many possible causes for an increasing proportion of incomplete injuries. New and improved acute treatment modalities may be having an impact. However, trends in age and etiology are also at least partly responsible because older persons are most likely injured in falls that result in incomplete tetraplegia. Moreover, gunshot-related SCIs are on the decline in the United States in the past decade, and these typically result in complete paraplegia. ${ }^{18}$

Given demographic trends in age and etiology, as well as the continued possibility of treatment advances and improved acute survival of high level injuries, it is likely that current trends toward an increasing percentages of C1-C4 injuries (about 2\% per decade), ventilator dependency (about $1 \%$ per decade) and incomplete injuries at all levels (about $2 \%$ per decade) will continue among new SCIs.

\section{Life expectancy}

On the basis of mortality rates from 2005 to 2009, among white males injured in motor vehicle crashes who have already survived at least 2 years after injury, the percentage who die each year by age and neurological category derived from the combined US data set appears in Table 1. White males injured in motor vehicle crashes were chosen because this is the most common combination of characteristics. Mortality rates for females and persons injured during sports activities will be slightly lower than seen in Table 1, whereas those of African Americans and persons injured by acts of violence, falls, or complications of medical or surgical procedures will be slightly higher than seen in Table 1.

Mortality rates are generally low at younger ages, but increase rapidly with advancing age, particularly $>60$ years for more severe injuries. Based on Table 1, the percentage of 50 -year-old persons who are still alive at age 60 would be $37.2 \%$ for ventilator-dependent persons, $59.2 \%$ for persons with C1-4 injuries, $67.9 \%$ for persons with C5-8 injuries, $78.0 \%$ for persons with paraplegia and $84.7 \%$ for persons with American Spinal Injury Association Injury Scale (AIS) D injuries, regardless of injury level. AIS D injuries are those for which at least half the key muscles below the injury level test at a grade of at least 3 out of 5 . The percentage of 50 -year-old persons reaching 70 years of age would be $6.9 \%$ for ventilator-dependent persons, $23.9 \%$ 
Table 1 Percentage of persons with $\mathrm{SCl}$ who die each year by age and injury severity ${ }^{\mathrm{a}}$

\begin{tabular}{|c|c|c|c|c|c|c|}
\hline Age & Ventilator-dependent & C1-C4 AIS ABC & $C 5-C 8 A I S A B C$ & T1-S5 AIS ABC & $A / S D$ & General population \\
\hline $20-24$ & 1.8 & 0.9 & 0.7 & 0.4 & 0.3 & 0.1 \\
\hline $30-34$ & 2.7 & 1.4 & 1.1 & 0.7 & 0.4 & 0.1 \\
\hline $35-39$ & 3.5 & 1.8 & 1.4 & 0.9 & 0.6 & 0.2 \\
\hline $40-44$ & 4.7 & 2.5 & 1.8 & 1.2 & 0.8 & 0.3 \\
\hline $55-59$ & 10.6 & 5.8 & 4.3 & 2.8 & 1.9 & 0.9 \\
\hline $60-64$ & 13.5 & 7.4 & 5.6 & 3.6 & 2.4 & 1.3 \\
\hline $65-69$ & 17.5 & 9.9 & 7.4 & 4.8 & 3.3 & 1.9 \\
\hline $70-74$ & 23.8 & 13.9 & 10.6 & 7.0 & 4.7 & 3.0 \\
\hline $75-79$ & 32.8 & 20.2 & 15.6 & 10.5 & 7.2 & 5.0 \\
\hline $80-84$ & 40.1 & 25.7 & 20.2 & 13.8 & 9.6 & 8.2 \\
\hline
\end{tabular}

Abbreviations: AIS D, American Spinal Injury Association Injury Scale D injuries; SCI, spinal cord injury.

aBased on mortality rates in 2005-2009 for white males injured in motor vehicle crashes who are 2-year survivors.

${ }^{b}$ Assumes age at injury $<16$ for the $0-19$ age category only. Other age categories assume age at injury $>15$.

for persons with $\mathrm{C} 1-4$ injuries, $34.3 \%$ for persons with $\mathrm{C} 5-8$ injuries, $50.8 \%$ for persons with paraplegia and $63.4 \%$ for persons with AIS D injuries. The corresponding percentages of the 50-year-old white male general population surviving to age 60 and age 70 are $92.9 \%$ and $78.8 \%$, respectively.

Detailed life expectancy tables have been produced by the NSCISC and are updated annually. ${ }^{26}$ Overall, life expectancies following SCI in the United States are substantial, but remain significantly below normal for all but the most incomplete injuries. ${ }^{27-31}$ These mortality rates and life expectancies are similar to those observed in other developed countries. ${ }^{32-35}$

Over the past four decades, considerable progress has been made toward reducing the mortality rate during the first year after injury. ${ }^{8}$ Based on the combined US data set, after adjusting for trends over time in age, gender, race, cause of injury, severity of injury and insurance status, the odds of dying in the first year after injury were 69\% lower between 2005 and 2009 than during the 1970s (unpublished data). Beyond the first year after injury, progress in reducing annual mortality rates has been much slower. ${ }^{8,27,28}$ During the 1980s, the annual odds of dying after the first post-injury year were reduced by $20 \%$ compared with the 1970 s. ${ }^{8}$ However, no meaningful reductions in annual mortality rates have occurred since the $1980 \mathrm{~s}^{8}$ As a result, the gap in life expectancy between the general population and persons with SCI is increasing.

Examination of the most frequent causes of death after SCI may offer some clues regarding this lack of progress in life expectancy after SCI. Considerable progress is being made in the prevention and treatment of chronic diseases such as heart disease, cancer and cerebrovascular disease, which are the leading causes of death in the general population. However, most deaths after SCI involve acute events such as pneumonia, respiratory failure, septicemia and other infective diseases, pulmonary embolus and external causes (unintentional injuries, suicide and homicide) ${ }^{28,36,37}$ Chronic disease mortality rates after SCI are only slightly elevated from those experienced by the general population, and as these causes of death typically occur later in life they have less impact on life expectancy than do acute diseases and external events occuring among younger individuals. ${ }^{36,37}$

\section{Overall prevalence}

Although incidence reflects the number of new cases of SCI that occur each year, prevalence is defined as the number of persons with an SCI who are currently alive. Prevalence is determined by both incidence and duration of illness, or in the case of SCI, life expectancy. If both incidence and life expectancy are constant over many years, then prevalence can be estimated as the product of incidence and life expectancy. Using this formula, prevalence of SCI in the United States was estimated to be 906 persons per million population in 1980 (30 per million incidence $\times 30.2$ years average life expectancy). ${ }^{38}$ This was likely an overestimate because a current estimate of life expectancy was used rather than the average life expectancy over the past 30 years.

Because SCI is a relatively rare condition, estimating prevalence by sampling the population requires a very large sample. As a result, very few attempts to estimate prevalence by sampling populations have been made. In 1988, using a sophisticated area sampling plan, the prevalence of SCI in the United States was estimated to be 721 per million population, or 176965 persons. ${ }^{39}$ Moreover, as more new SCIs were occurring each year than deaths among those who already had SCI, prevalence was projected to increase to 246882 persons by 2004 and 276281 persons by $2014 .{ }^{40}$ This represents an average increase of 4370 per year between 1988 and 2004, but only 2940 per year between 2004 and 2014. Without significant changes in incidence or life expectancy, prevalence in the United States will continue to increase at a decelerating pace until the number of new injuries each year equals the number of deaths.

There have been six studies of SCI prevalence outside the United States, three of which were in Scandinavia. In Stockholm, Sweden, in the early 1990s, prevalence of SCI was estimated to be 227 persons per million population. ${ }^{41}$ In Norway, SCI prevalence in 2002 was 365 persons per million population. ${ }^{21}$ In Helsinki, Finland, SCI prevalence was 280 persons per million population in $1999 .{ }^{42}$ In Tehran, Iran, SCI prevalence in 2008 was estimated to be 440 persons per million population, but the confidence interval was wide ( $95 \%$ confidence interval $=120-1140$ per million) because only four actual cases of SCI were identified from the sample. ${ }^{43}$ In Australia, SCI prevalence in 1997 was estimated to be 681 persons per million population, with a 
projected increase of $20 \%$ by 2021 if age-specific SCI incidence rates remained unchanged. ${ }^{44}$

Recently, the prevalence of SCI in Canada was estimated to be 1289 persons per million population, or 43974 persons living with SCI in 2010 (http://rickhanseninstitute.org/images/stories/sci-in-canada13dec10.pdf. Accessed 12/17/2010). Because current estimates of the percentage of normal life expectancy experienced by persons with SCI were applied retroactively as far back as 1921, this will result in an overestimate of prevalence. Given the estimate of a 40.7 per million incidence rate used in the Canadian study and their use of US life expectancy data, the estimate of prevalence in Canada should be comparable to prevalence of SCI in the United States.

Results of a recent study of SCI prevalence in the United States sponsored by the Christopher and Dana Reeve Foundation have also been posted on the foundation's web site (http://www.christopherreeve. org/site/c.mtKZKgMWKwG/b.5184189/k.5587/Paralysis_Facts_Figures. htm. Accessed 12/9/2010). On the basis of a random sample telephone survey of self-reported paralysis because of SCI and without independent confirmation, SCI prevalence was estimated to be 1263000 persons, or 4091 persons per million population. This estimate is considerably higher than any other estimate of SCI prevalence anywhere in the world.

Unfortunately, despite efforts to screen out non-traumatic SCI, it appears that many of the self-identified cases of SCI found in this study are not cases of traumatic SCI as traditionally defined, but are likely transient spinal injuries such as disc herniations, pinched nerves, degenerative joint disease and so on. This view is supported by the descriptive characteristics of the purported prevalent population. Approximately 160000 persons were estimated to have had their SCI for $\leqslant 3$ years, which would translate to an incidence rate in excess of 50000 new injuries each year (four times the results of previous population-based estimates of SCI incidence). Moreover, the decline in estimated prevalent cases each year after injury is much higher than current mortality estimates, suggesting that many cases are being cured. The average duration of injury was estimated to be only 14 years, which should equal the life expectancy if incidence and life expectancy have been relatively constant over time, but average life expectancy has been shown from other studies to be in excess of 30 years.

Other characteristics of the SCI prevalent population reported by the Christopher and Dana Reeve Foundation also appear to be out of line with previous studies. Approximately $39 \%$ of persons with SCI were reported to be females compared with about $20 \%$ in other studies. Work-related injuries were three times more prevalent (30\%) than in the combined US data set (10\%). Finally, only $13 \%$ reported being completely unable to move, which is lower than found in other studies. Therefore, although overall results describing the prevalence of paralysis as defined in the study may be valid, results reflecting traumatic SCI from this study should be discounted unless confirmed by another study with more rigorous case ascertainment procedures.

Current age. The mean age of persons alive in December 2008 who were enrolled in the combined US data set was 45.4 years, compared with 40.2 years for persons alive in 2000, and 35.9 years for persons alive in $1990 .{ }^{9}$ Persons who were at least 60 years of age were $15.7 \%$ in 2008, $9.6 \%$ in 2000 and $7.2 \%$ in $1990 .{ }^{9}$ However, estimates of the characteristics of the prevalent SCI population derived from the combined US data set are increasingly biased by exclusion of longterm survivors as they go back in time. Therefore, the actual increase in the current age of the prevalent SCI population is less than suggested by the previous statistics. In the 1988 study of US pre- valence, median age was 41 years, and this would likely be more accurate than contemporaneous estimates from the combined US data set. ${ }^{39}$ Given the high annual mortality rates shown earlier for older persons with SCI, it is likely that the average age of the prevalent population will increase at a slower pace in the future and may eventually plateau, likely $<60$ years of age.

The percentage of persons with SCI in Canada who are alive in 2010 and at least 60 years of age is estimated to be $36.2 \%$ (http:// rickhanseninstitute.org/images/stories/sci-in-canada-13dec10.pdf. Accessed 12/17/2010). This is considerably higher than in the United States, and is probably an overestimate owing to the application of current relative survival rates to calendar years in the 1970s and earlier.

Gender. Females should constitute a slightly higher proportion of the prevalence population than they do for new injuries because of their lower annual mortality rates. In the 1988 US study, 29\% were women. ${ }^{39}$ However, in the combined US data set, only $22 \%$ of persons alive in 2008 were women. ${ }^{9}$ In Hordaland County, Norway, SCI prevalence was 601 per million for men and 104 per million for women, whereas in Sogn og Fjordane County, Norway, the comparable figures were 662 and 170, respectively. ${ }^{21}$ Interestingly, the excess of men over women was greatest among persons $>60$ years of age. ${ }^{21}$ In Helsinki, Finland, the prevalence of SCI among men was 460 per million compared with 120 per million among women. ${ }^{42}$ Given the slight trend toward a greater proportion of women among new injuries as well as their slightly greater survival rates, the proportion of women in the prevalent population will continue to increase, but very slowly.

Injury severity. Unlike the trend toward increasing numbers of highlevel cervical injuries among incident cases, no such trend has occurred among prevalent cases. Overall, $48 \%$ of persons alive in 2008 who were enrolled in the combined US data set had cervical injuries, compared with $49.4 \%$ of persons alive in 2000 , and $49.7 \%$ of persons alive in $1990 .{ }^{9}$ This lack of trend is because the high mortality rates observed by persons with cervical injuries offset the increasing numbers of new cervical injuries.

In Canada, $56.3 \%$ of persons with SCI alive in 2010 were estimated to have cervical injuries. This is consistent with the higher incidence of cervical injuries in Canada $(56.7 \%$ cervical vs $43.3 \%$ thoracic or below) (http://rickhanseninstitute.org/images/stories/sci-in-canada-13 dec10.pdf. Accessed 12/17/2010).

Similarly, there is no meaningful trend in the proportion of persons with neurologically complete injuries in the prevalent population. Among persons enrolled in the combined US data set who were alive in 2008, 50.4\% had neurologically complete injuries compared with $53.2 \%$ of persons alive in 2000 , and $51.7 \%$ of persons alive in $1990 .^{9}$

\section{Health status and treatment outcomes}

Given the aforementioned trends in demographics and injury severity for both new injuries and persons in the prevalent population as well as the absence of trend in mortality rates beyond the first year after injury, several negative trends in overall health and function, community integration and treatment outcomes can be anticipated in the next decade. These can be offset and possibly reversed by new and improved treatment practices.

As the percentage of new injuries over the age of 60 increases, so will the occurrence of preexisting major medical conditions that could make acute care and rehabilitation treatment more difficult. In one US study conducted during the 1970 s and 1980 s, $24.3 \%$ of persons with SCI who were $>60$-year-old at injury had arthritis, $8.6 \%$ had 
significant heart disease, $4.3 \%$ had diabetes and $4.3 \%$ were obese. ${ }^{45}$ These figures were all significantly higher than those of younger age groups, and will likely be higher today given general population trends toward greater obesity.

Older persons tend to have less functional ability at rehabilitation discharge. Based on NSCISC data, $56.2 \%$ of persons aged $46-60$ were independent in self care activities at discharge, compared with $39.5 \%$ at age $61-75$, and only $29.1 \%$ at age $\geqslant 76.46$ Rasch-converted motor scores of the Functional Independence Measure (FIM) are 11.4 points lower for persons aged 75-79 compared with persons aged 18-29.47 When combined with higher average injury levels and reduced lengths of stay, it is not surprising that mean discharge motor FIM scores have declined from 62 during 1987-1991 to only 52 during 2002-2006. ${ }^{8}$ Moreover, despite increased use of outpatient therapy, lower FIM motor scores persist at first anniversary of injury. ${ }^{48}$

Older age at injury is associated with a significantly higher likelihood of discharge to a nursing home both in the United States (9\% for age $46-60,15.9 \%$ for age $61-75$ and $28.5 \%$ for age $\geqslant 76$ ) and Canada $(5.5 \%$ increased risk per year of increased age for C1-4 injuries). ${ }^{49,50}$ Higher injury level is also associated with an increased probability of nursing home discharge $(2.5 \%$ for T1-T12, $4.9 \%$ for $\mathrm{C} 5-\mathrm{C} 8$ and $9 \%$ for $\mathrm{C} 1-\mathrm{C} 4) .{ }^{49}$ Moreover, those who are not independent in self care are 2.11 times more likely to be discharged to a nursing home. ${ }^{49}$ Therefore, it is not surprising that the percentage of nursing home discharges more than doubled between 1970 and 2008 (5-10.8\%). ${ }^{9}$ Given these risk factor trends, by $2020,13-15 \%$ of SCI discharges will likely be to nursing homes.

In 2008, $4.6 \%$ of persons in the combined US data set were residing in nursing homes. ${ }^{9}$ However, this figure will increase more slowly than the trend in nursing home discharges because mortality rates among persons with SCI who reside in nursing homes are more than twice as high, all other things equal, as those living in private residences (unpublished NSCISC data).

Medical complication rates also greatly increase with advancing age. Among persons $>60$ years of age at injury, $47 \%$ had at least one pressure sore during initial hospitalization, 30\% developed pneumonia, $11.4 \%$ had deep vein thrombosis, $10 \%$ had a gastrointestinal hemorrhage and $5.7 \%$ had a renal stone. ${ }^{45}$ Long-term medical complication rates also increase with both older age and greater injury severity. ${ }^{51-55}$ During the 5th post-injury year, among persons who are $>60$ years of age, $7.1 \%$ develop pneumonia and $29.5 \%$ have abnormal renal function. $^{52}$ The corresponding figures for persons $<40$ years of age are $2.2 \%$ for pneumonia and $10.2 \%$ for abnormal renal function. ${ }^{52}$ The long-term odds of developing a kidney stone are $50 \%$ higher for persons who are at least 55 years of age compared with those who are aged 25-34, and $90 \%$ higher for persons with tetraplegia compared with persons with AIS D injuries. ${ }^{54}$ After controlling for other risk factors, the odds of developing a pressure ulcer are $30 \%$ higher among persons who are at least 50 years of age compared with those who are aged 15-29. ${ }^{51}$

As a result, it is not surprising that long-term medical complication rates have been increasing over the past two decades. ${ }^{8}$ During the 5 th post-injury year, the incidence of pneumonia has increased from $2.5 \%$ during 1987-1991 to 4.1\% from 2002-2006. Corresponding increases in other medical complication rates were $0.4-2.6 \%$ for deep vein thrombosis, $0.2-0.7 \%$ for pulmonary embolus, $3.9-6.1 \%$ for skin flap surgery and $2.0-3.4 \%$ for renal stones. ${ }^{8}$ The long-term odds of developing a pressure ulcer were 40\% higher during 1994-2002 compared with 1986-1993. ${ }^{51}$

Given these increased medical complication rates, higher injury levels and advancing age of persons with SCI, one would expect higher rehospitalization rates and increased days hospitalized over time. ${ }^{56}$
During the late 1980s, the SCI rehospitalization rate was 524 per 1000 persons aged $61-75$, but only 398 per 1000 persons aged $31-45{ }^{46}$ However, despite higher hospitalization rates among the elderly, during the 1970s and 1980s, average days re-hospitalized per year actually declined over time, due most likely to changes in the US health care system that led to an increased share of complications being treated on an outpatient basis. ${ }^{855}$ Over the more recent time period from 1992-2006, mean days hospitalized during the 5th postinjury year increased from 3.4 to 5.7 .8

Over the next two decades, because of a combination of risk factor trends that includes advancing age, higher injury levels and longer average duration of injury, changes should occur in the leading causes of death. Pneumonia will likely retain its number 1 ranking, but heart disease and cancer will increase proportionately, whereas external causes of death (unintentional injuries, suicide and homicide) will decline in rank. ${ }^{36,37}$

Psychosocial outcomes are less highly correlated with either age or injury severity, and should therefore be less affected by trends in these risk factors over time. Although average scores on each subscale of the Craig Hospital Assessment and Reporting Technique (CHART) decline slightly with advancing age, average scores actually increased from 1992 to $2006 .^{8,47,57}$ Satisfaction with life scores are similar across age groups, whereas self-perceived health declines only slightly. ${ }^{47}$ One cohort study showed that measures of quality of life and self-perceived health were quite stable throughout the 1990s. ${ }^{58}$

\section{Cross-sectional versus cohort studies}

Cross-sectional study designs have been used extensively to study the long-term outcomes of persons with SCI. These are studies in which, ideally, a random sample from the prevalent SCI population is evaluated in terms of the outcome of interest and the factors associated with that outcome. One such factor is typically the number of years after injury. Many such cross-sectional studies have shown that outcomes are at least as good or better 20-30 years after injury than they are during the first few years after injury. For example, both Craig Hospital Assessment and Reporting Technique and satisfaction with life scores are higher for persons with a longer duration of SCI. ${ }^{57,59}$ Self-reported health and FIM motor scores are essentially the same at 5 and 30 years after injury. ${ }^{9,59}$ The percentage of persons who are rehospitalized at 30 years after injury is lower than the percentage rehospitalized during post-injury year $5 .{ }^{9}$ Conversely, many studies also show that older persons have lower Craig Hospital Assessment and Reporting Technique and FIM motor scores as well as higher rehospitalization rates. ${ }^{46,47,57}$

These somewhat conflicting findings can be explained by the impact of a bias related to differential survival over time. Those individuals who are doing poorly do not typically live as long. In fact, the average age for persons in the combined US data set who are 5 years after injury is 41.4 years whereas the average age of persons who are 30 years after injury is only 12.5 years higher, not 25 years higher. ${ }^{9}$ As a result, those who are still alive 30 years after injury tend to be less severely impaired on average than persons who are only 5 years after injury, and they tend to be doing well. Because of this differential survival bias, it is not possible to make inferences regarding changes over time from cross-sectional studies. Such inferences can only be made by conducting cohort studies.

Cohort studies are those that enroll individuals and follow them over time. These study designs typically involve repeated measures and require more sophisticated analytical methods, such as linear mixed models or generalized estimating equations. Few such SCI studies have been conducted. ${ }^{51,53}$ Another approach that has been used in SCI 
survival studies and could have other applications is the pooled repeated observations method where each person-year of follow-up is treated as a separate observation to help distinguish the effects of age, time postinjury and calendar year, all of which advance simultaneously. ${ }^{19}$

\section{Non-traumatic SCI}

The previous discussion of incidence, life expectancy, and prevalence has focused entirely on traumatic SCI. During the past decade, investigators have begun to consider the epidemiology of nontraumatic SCI or a combination of both traumatic and non-traumatic SCI referred to as spinal cord dysfunction. Unfortunately, there is no consensus on the definition of non-traumatic SCI or what diagnoses should be included under this umbrella term. Moreover, outcomes will vary substantially on the basis of whether the underlying condition is progressive (such as spinal cord tumors) or stable.

Although it is not the intent of this review to evaluate the epidemiology of non-traumatic SCI or spinal cord dysfunction, a few brief generalizations can be made. First, by almost any definition, non-traumatic SCI has a higher incidence than traumatic SCI. Studies in Australia and Canada indicate that the incidence of non-traumatic SCI is $60-70 \%$ higher than that of traumatic SCI (http://rickhanseninstitute.org/images/stories/sci-in-canada-13dec10.pdf. Accessed 12/17/2010). ${ }^{60}$ Persons who develop non-traumatic SCI tend to be older, are more likely to be females and less likely to have cervical spinal cord involvement than persons who sustain a traumatic SCI. However, because persons with non-traumatic SCI are older at diagnosis and some have progressive conditions with relatively poor prognoses, average life expectancy is lower for non-traumatic SCI than traumatic SCI. Therefore, at least in Canada, despite its higher incidence, prevalence is actually 5\% lower for non-traumatic SCI than traumatic SCI (http://rickhanseninstitute.org/images/stories/sci-incanada-13dec10.pdf. Accessed 12/17/2010). Studies will need to be done in other locations to confirm this interesting finding.

\section{CONCLUSIONS}

\section{Demographics}

The average age of both newly injured persons and all persons who are currently alive with SCI will increase slowly. The percentage of new injuries occurring among persons $>60$ years of age will increase, but the percentage of the overall SCI population $>60$ years of age will increase more slowly because of high mortality rates among older persons with SCI. Similarly, the percentage of higher injury levels will increase among new injuries but remain relatively stable in the overall SCI population.

\section{Outcomes}

The trends toward higher injury levels and older age at injury will provide significant challenges for research. Increasing likelihood of preexisting medical conditions and secondary medical complications will mean that a higher percentage of persons will not meet eligibility criteria for research studies. Older individuals are more likely to have cognitive difficulties that might make them less willing to participate, harder to follow long-term and less compliant with study protocols. Shorter lengths of stay in rehabilitation and increasing discharges to nursing homes will make it more difficult for participants to complete study protocols prior to discharge.

Overall treatment outcomes will be less favorable in the future owing to trends in age and injury severity. However, those who reach older ages after surviving many years after injury will typically have incomplete and/or lower level injuries, and will have relatively high degrees of independence and overall good health. Nonetheless, given unfavorable overall trends, the use of multivariate statistical techniques will be necessary to adjust for these risk factor trends before evaluating whether actual progress is being made in treatment outcomes.

\section{Study design}

Future epidemiological efforts should focus on developing a more accurate profile of persons with SCI who are alive today (prevalence), as this has received much less attention than corresponding studies of SCI incidence. Studies of incidence should be population-based and include an analysis of trends over time whenever possible. Detailed investigations of the exact circumstances surrounding how these injuries occur are also needed. Such research might provide important clues to developing cost-effective primary prevention strategies.

Cross-sectional studies should be used to evaluate the current status of persons in the overall SCI population (prevalence). Changes over time, as people age, should only be assessed by conducting cohort studies. Data collection and reporting should be in accordance with the International SCI Core Data Set and other International SCI Data Sets to facilitate meaningful comparisons across studies. ${ }^{61,62}$

\section{Non-traumatic SCI}

The definition of non-traumatic SCI needs to be standardized so that studies can be compared more readily. Results of studies of non-traumatic SCI need to be stratified by underlying diagnosis, or at a minimum, progressive diseases need to be separated from nonprogressive ones.

\section{CONFLICT OF INTEREST}

The author declares no conflict of interest.

\section{ACKNOWLEDGEMENTS}

This work was supported by the National Institute on Disability and Rehabilitation Research

1 Kraus JF, Franti CE, Riggins RS, Richards D, Borhani NO. Incidence of traumatic spinal cord lesions. J Chron Dis 1975; 28: 471-492.

2 Griffin MR, Opitz JL, Kurland LT, Ebersold MJ, O'Fallon WM. Traumatic SCl in Olmsted County, Minnesota, 1935-1981. Am J Epidemiol 1985; 121: 884-895.

3 Bracken MB, Freeman DH, Hellenbrand K. Incidence of acute traumatic hospitalized spinal cord injury in the United States, 1970-1977. Am J Epidemiol 1981; 113: 615-622.

4 DeVivo MJ. Model spinal cord injury systems of care. In: Lin VW (ed). Spinal Cord Medicine Principles and Practice. Demos Medical Publishing: New York, NY, 2010, pp 1059-1062.

5 Nobunaga AI, Go BK, Karunas RB. Recent demographic and injury trends in people served by the model spinal cord injury care systems. Arch Phys Med Rehabil 1999; 80: $1372-1382$

6 Jackson AB, Dijkers M, DeVivo MJ, Poczatek RB. A demographic profile of new traumatic spinal cord injuries: change and stability over 30 years. Arch Phys Med Rehabil 2004; 85: 1740-1748.

7 DeVivo MJ, Vogel LC. Epidemiology of spinal cord injury in children and adolescents. J Spinal Cord Med 2004; 27(Suppl): S4-S10.

8 DeVivo MJ. Trends in spinal cord injury rehabilitation outcomes from model systems in the United States: 1973-2006. Spinal Cord 2007; 45: 713-721.

9 DeVivo MJ, Chen Y. Trends in new injuries, prevalent cases, and aging with spinal cord injury. Arch Phys Med Rehabil 2011; 92: 332-338.

10 Stover SL, DeVivo MJ, Go BK. History, implementation, and current status of the national spinal cord injury database. Arch Phys Med Rehabil 1999; 80: 1365-1371.

11 DeVivo MJ, Go BK, Jackson AB. Overview of the national spinal cord injury statistical center database. J Spinal Cord Med 2002; 25: 335-338.

12 Price C, Makintubee S, Herndon W, Istre GR. Epidemiology of traumatic spinal cord injury and acute hospitalization and rehabilitation charges for spinal cord injuries in Oklahoma, 1988-1990. Am J Epidemiol 1994; 139: 37-47.

13 Thurman DJ, Burnett CL, Jeppson L, Beaudoin DE, Sniezek JE. Surveillance of spinal cord injuries in Utah, USA. Paraplegia 1994; 32: 665-669.

14 Surkin J, Smith M, Penman A, Currier M, Harkey HL, Chang Y-F. Spinal cord injury incidence in Mississippi: a capture-recapture approach. J Trauma 1998; 45: 502-504.

15 Acton PA, Farley T, Freni T, Ilegbodu VA, Sniezek JE, Wohlleb JC. Traumatic spinal cord injury in Arkansas, 1980-1989. Arch Phys Med Rehabil 1993; 74: 1035-1040. 
16 Johnson RL, Gabella BA, Gerhart KA, McCray J, Menconi JC, Whiteneck GG. Evaluating sources of traumatic spinal cord injury surveillance data in Colorado. Am J Epidemiol 1997; 146: 266-272.

17 Go BK, DeVivo MJ, Richards JS. The epidemiology of spinal cord injury. In: Stover SL, DeLisa JA, Whiteneck GG (eds). Spinal Cord Injury: Clinical Outcomes from the Model Systems. Aspen Publishers: Gaithersburg, MD, 1995, pp 21-55.

18 DeVivo MJ. Epidemiology of spinal cord injury. In: Lin VW (ed). Spinal Cord Medicine Principles and Practice. Demos Medical Publishing: New York, NY, 2010, pp 78-84.

19 Strauss D, Shavelle R, DeVivo MJ, Day S. An analytic method for longitudinal mortality studies. J Insur Med 2000; 32: 217-225.

20 Glick T. SCl surveillance: is there a decrease in incidence? [abstract]. J Spinal Cord Med 2000; 23(Suppl): 61.

21 Hagen EM, Eide GE, Rekand T, Gilhus NE, Gronning M. A 50-year follow-up of the incidence of traumatic spinal cord injuries in Western Norway. Spinal Cord 2010; 48: 313-318.

22 Ahoniemi E, Alaranta H, Hokkinen E-M, Valtonen K, Kautiainen H. Incidence of traumatic spinal cord injuries in Finland over a 30-year period. Spinal Cord 2008; 46: 781-784.

23 O'Connor PJ. Trends in spinal cord injury. Accident Anal Prev 2006; 38: 71-77.

24 O'Connor PJ. Forcasting of spinal cord injury annual case numbers in Australia. Arch Phys Med Rehabil 2005; 86: 48-51.

25 Exner G, Meinecke FW. Trends in the treatment of patients with spinal cord lesions seen within a period of 20 years in German centers. Spinal Cord 1997; 35: 415-419.

26 National Spinal Cord Injury Statistical Center. Spinal cord injury facts and figures at a glance. J Spinal Cord Med 2010; 33: 439-440.

27 Strauss DJ, DeVivo MJ, Paculdo DR, Shavelle RM. Trends in life expectancy after spinal cord injury. Arch Phys Med Rehabil 2006; 87: 1079-1085.

28 DeVivo MJ, Krause JS, Lammertse DP. Recent trends in mortality and causes of death among persons with spinal cord injury. Arch Phys Med Rehabil 1999; 80: 1411-1419.

29 Krause JS, DeVivo MJ, Jackson AB. Health status, community integration, and economic risk factors for mortality after spinal cord injury. Arch Phys Med Rehabil 2004; 85: 1764-1773.

30 Shavelle RM, DeVivo MJ, Paculdo DR, Vogel LC, Strauss DJ. Long-term survival after childhood spinal cord injury. J Spinal Cord Med 2007; 30(Suppl): S48-S54.

31 Shavelle RM, DeVivo MJ, Strauss DJ, Paculdo DR, Lammertse DP, Day SM. Long-term survival in persons ventilator dependent after spinal cord injury. J Spinal Cord Med 2006; 29: 511-519.

32 Lidal IB, Snekkevik H, Aamodt G, Hjeltnes N, Stanghelle JK, Biering-Sorensen F. Mortality after spinal cord injury in Norway. J Rehabil Med 2007; 39: 145-151.

33 Hartkopp A, Bronnum-Hansen H, Seidenschnur A-M, Biering-Sorensen F. Survival and cause of death after traumatic spinal cord injury: a long-term epidemiological survey from Denmark. Spinal Cord 1997; 35: 78-85.

34 O'Connor PJ. Survival after spinal cord injury in Australia. Arch Phys Med Rehabil 2005: 86: 37-47.

35 Frankel HL, Coll JR, Charlifue SW, Whiteneck GG, Gardner BP, Jamous MA et al. Longterm survival in spinal cord injury: a fifty-year investigation. Spinal Cord 1998; 36: 266-274.

36 DeVivo MJ, Black KJ, Stover SL. Causes of death during the first 12 years after spinal cord injury. Arch Phys Med Rehabil 1993; 74: 248-254.

37 DeVivo MJ, Stover SL. Long-term survival and causes of death. In: Stover SL, DeLisa JA, Whiteneck GG (eds). Spinal Cord Injury: Clinical Outcomes from the Model Systems. Aspen Publishers: Gaithersburg, MD, 1995, pp 289-316.

38 DeVivo MJ, Fine PR, Maetz HM, Stover SL. Prevalence of spinal cord injury: a reestimation based on life table techniques. Arch Neurol 1980; 37: 707-708.

39 Berkowitz M, Harvey C, Greene CG, Wilson SE. The Economic Consequences of Traumatic Spinal Cord Injury. Demos Publishers: New York, 1992, pp 35-71.
40 Lasfargues JE, Custis D, Morrone F, Carswell J, Nguyen T. A model for estimating spinal cord injury prevalence in the United States. Paraplegia 1995; 33: 62-68.

41 Levi R, Hulting C, Nash MS, Seiger A. The Stockholm spinal cord injury study: 1. Medical problems in a regional SCl population. Paraplegia 1995; 33: 308-315.

42 Dahlberg A, Kotila M, Leppanen P, Kautiainen H, Alaranta H. Prevalence of spinal cord injury in Helsinki. Spinal Cord 2005; 43: 47-50.

43 Rahimi-Movaghar V, Saadat S, Rasouli MR, Ganji S, Ghahramani M, Zarei M-R et al. Prevalence of spinal cord injury in Tehran, Iran. J Spinal Cord Med 2009; 32: 428-431.

44 O'Connor PJ. Prevalence of spinal cord injury in Australia. Spinal Cord 2005; 43 : 42-46.

45 DeVivo MJ, Kartus PL, Rutt RD, Stover SL, Fine PR. The influence of age at time of spinal cord injury on rehabilitation outcome. Arch Neurol 1990; 47: 681-691.

46 DeVivo MJ, Shewchuk RM, Stover SL, Black KJ, Go BK. A cross-sectional study of the relationship between age and current health status for persons with spinal cord injury. Paraplegia 1992; 30: 820-827.

47 Putzke JD, Barrett JJ, Richards JS, DeVivo MJ. Age and spinal cord injury: an emphasis on outcomes among the elderly. J Spinal Cord Med 2003; 26: 37-44.

48 Kogos SC, DeVivo MJ, Richards JS. Recent trends in spinal cord injury rehabilitation practices and outcomes. Top Spinal Cord Inj Rehabil 2004; 10: 49-57.

49 DeVivo MJ. Discharge disposition from model spinal cord injury care system rehabilitation programs. Arch Phys Med Rehabil 1999; 80: 785-790.

50 Anzai K, Young J, McCallum J, Miller B, Jongbloed L. Factors influencing discharge location following high lesion spinal cord injury rehabilitation in British Columbia, Canada. Spinal Cord 2006; 44: 11-18.

51 Chen Y, DeVivo MJ, Jackson AB. Pressure ulcer prevalence in people with spinal cord injury: age-period-duration effects. Arch Phys Med Rehabil 2005; 86: 1208-1213.

52 McKinley WO, Jackson AB, Cardenas DD, DeVivo MJ. Long-term medical complications after traumatic spinal cord injury: a regional model systems analysis. Arch Phys Med Rehabil 1999; 80: 1402-1410.

53 Sekar P, Wallace DD, Waites KB, DeVivo MJ, Lloyd LK, Stover SL et al. Comparison of long-term renal function after spinal cord injury using different urinary management methods. Arch Phys Med Rehabil 1997; 78: 992-997.

54 Chen Y, DeVivo MJ, Roseman JM. Current trend and risk factors for kidney stones in persons with spinal cord injury: a longitudinal study. Spinal Cord 2000; 38: 346-353.

55 DeVivo MJ, Fine PR. Predicting renal calculus occurrence in spinal cord injury patients. Arch Phys Med Rehabil 1986; 67: 722-725.

56 Ivie CS, DeVivo MJ. Predicting unplanned hospitalizations in persons with spinal cord injury. Arch Phys Med Rehabil 1994; 75: 1182-1188.

57 Whiteneck G, Tate D, Charlifue S. Predicting community reintegration after spinal cord injury from demographic and injury characteristics. Arch Phys Med Rehabil 1999; 80: 1485-1491.

58 Charlifue S, Gerhart K. Changing psychosocial morbidity in people aging with spinal cord injury. NeuroRehabil 2004; 19: 15-23.

59 Charlifue S, Lammertse DP, Adkins RH. Aging with spinal cord injury: changes in selected health indices and life satisfaction. Arch Phys Med Rehabil 2004; 85: 1848-1853.

60 New PW, Simmonds F, Stevermuer T. A population-based study comparing traumatic spinal cord injury and non-traumatic spinal cord injury using a national rehabilitation database. Spinal Cord 2011; 49: 397-403.

61 DeVivo M, Biering-Sorensen F, Charlifue S, Noonan V, Post M, Stripling T et al. International spinal cord injury core data set. Spinal Cord 2006; 44: 535-540.

62 DeVivo MJ, Biering-Sorensen F, New P, Chen Y. Standardization of data analysis and reporting of results from the international spinal cord injury core data set. Spinal Cord 2011; 49: 596-599. 